\title{
Antidepressant-Induced Neurogenesis in the Hippocampus of Adult Nonhuman Primates
}

\author{
Tarique D. Perera, ${ }^{1,4}$ Jeremy D. Coplan, ${ }^{1,6}$ Sarah H. Lisanby, ${ }^{2,4}$ Cecilia M. Lipira, ${ }^{1}$ Mohamed Arif, ${ }^{6}$ Cristina Carpio, ${ }^{1}$ \\ Gila Spitzer, ${ }^{1}$ Luca Santarelli, ${ }^{3}$ Bruce Scharf, ${ }^{6}$ Rene Hen, ${ }^{3}$ Gorazd Rosoklija, ${ }^{2,4,7}$ Harold A. Sackeim, ${ }^{1,4}$ and \\ Andrew J. Dwork $2,4,5$ \\ Departments of ${ }^{1}$ Biological Psychiatry and ${ }^{2}$ Neuroscience, and ${ }^{3}$ The Center for Neurobiology and Behavior, New York State Psychiatric Institute New York, \\ New York 10032, Departments of ${ }^{4}$ Psychiatry and ${ }^{5}$ Pathology, College of Physicians and Surgeons, Columbia University Medical Center, New York, New \\ York 10032, ${ }^{6}$ Department of Psychiatry, State University of New York at Brooklyn, New York, New York 11203, and Macedonian Academy of Science and \\ Arts, 1000 Skopje, Republic of Macedonia
}

New neurons are generated in the adult hippocampus of many species including rodents, monkeys, and humans. Conditions associated with major depression, such as social stress, suppress hippocampal neurogenesis in rodents and primates. In contrast, all classes of antidepressants stimulate neuronal generation, and the behavioral effects of these medications are abolished when neurogenesis is blocked. These findings generated the hypothesis that induction of neurogenesis is a necessary component in the mechanism of action of antidepressant treatments. To date, the effects of antidepressants on newborn neurons have been reported only in rodents and tree shrews. This study examines whether neurogenesis is increased in nonhuman primates after antidepressant treatment. Adult monkeys received repeated electroconvulsive shock (ECS), which is the animal analog of electroconvulsive therapy (ECT), the most effective short-term antidepressant. Compared with control conditions, ECS robustly increased precursor cell proliferation in the subgranular zone (SGZ) of the dentate gyrus in the monkey hippocampus. A majority of these precursors differentiated into neurons or endothelial cells, while a few matured into glial cells. The ECS-mediated induction of cell proliferation and neurogenesis was accompanied by increased immunoreactivity for the neuroprotective gene product BCL2 (B cell chronic lymphocytic lymphoma 2) in the SGZ. The ECS interventions were not accompanied by increased hippocampal cell death or injury. This study demonstrates that ECS is capable of inducing neurogenesis in the nonhuman primate hippocampus and supports the possibility that antidepressant interventions produce similar alterations in the human brain.

Key words: antidepressants; electroconvulsive shock; depression; neurogenesis; monkey; hippocampus

\section{Introduction}

Newborn neurons are detected in the dentate gyrus of the hippocampus(Altman and Das, 1965) and the olfactory bulb (Pencea et al., 2001) of adult mammals, including monkeys (Gould et al., 1999; Kornack and Rakic, 1999; Pencea et al., 2001; Bernier et al., 2002) and humans (Eriksson et al., 1998). Conditions associated with major depression in humans, such as stress (Gould et al., 1999; Fuchs et al., 2001; Coe et al., 2003; Malberg and Duman, 2003; Pham et al., 2003) and drug abuse (Eisch et al., 2000; He et al., 2005), suppress neurogenesis in the hippocampus. This may contribute to the decreased hippocampal volume (Sheline et al.,

\footnotetext{
Received Jan. 18, 2007; revised March 28, 2007; accepted March 30, 2007.

This work was supported by National Institute of Mental Health Grants R01 MH35636 (H.A.S.), R01MH59990 (J.D.C.), and K08 MH70954 (T.D.P), the American Psychiatric Association Lilly Research Fellowship Award (T.D.P), and a Young Investigator Award from the National Alliance for Research on Schizophrenia and Depression (T.D.P). We thank Drs. Richard Nowakowski, Husseini Manji, and Robert Burke for sharing and assisting with several of the protocols used in this investigation. We are grateful for technical assistance of Dr. Vilas Patel, Mohammed Anwar, Poshala Aluwihare, and Rohan Sobby.

Correspondence should be addressed to Dr. Tarique Perera, Unit \#126, New York Psychiatric Institute/Columbia University, 1051 Riverside Drive, New York, NY 10032. E-mail: tp119@columbia.edu.

L. Santarelli's present address: Roche Inc., Palo Alto, CA 94304

DOI:10.1523/JNEUROSCI.0237-07.2007

Copyright $\odot 2007$ Society for Neuroscience $\quad$ 0270-6474/07/274894-08\$15.00/0
}

1999) and hippocampal dysfunction resulting in memory deficits (MacQueen et al., 2003) and hypothalamic-pituitary-adrenal axis hyperactivity (O'Brien et al., 1996) associated with subpopulations of patients with major depression. However, the suppression of neurogenesis is apparently not essential for inducing depression because hippocampal precursor proliferation is not reduced postmortem in depressed humans (Reif et al., 2006), nor in rats that develop learned helplessness (a model of depression) (Vollmayr et al., 2003). In contrast, the induction of neurogenesis seems to be necessary for antidepressant treatment (Perera and Lisanby, 2000). All major classes of antidepressants (Malberg et al., 2000; Manev et al., 2001; Santarelli et al., 2003; Sairanen et al., 2005) and electroconvulsive shock (ECS) (Madsen et al., 2000; Malberg et al., 2000; Scott et al., 2000; Hellsten et al., 2002) stimulate neurogenesis, as do interventions with antidepressant potential such as mood stabilizers (Chen et al., 2000; Hao et al., 2004), atypical antipsychotics (Wakade et al., 2002; Kodama et al., 2004), exercise (van Praag et al., 1999), and environmental enrichment (Kempermann et al., 1997). Blocking neurogenesis by irradiation of hippocampal precursor cells abolishes the therapeutic effects of antidepressants in mice exposed to chronic stress (Santarelli et al., 2003). Although the effects of social stress 
on neurogenesis have been documented in monkeys (Gould et al., 1998), the impact of antidepressants on neurogenesis is known only in rodents (Madsen et al., 2000; Malberg et al., 2000; Scott et al., 2000; Manev et al., 2001; Hellsten et al., 2002; Malberg and Duman, 2003; Santarelli et al., 2003) and tree shrews (Gould et al., 1997; Czeh et al., 2001, 2002). This study determines whether antidepressants stimulate neurogenesis in the primate hippocampus. After treating adult Old World (bonnet macaque) monkeys with a course of ECS, the animal analog of electroconvulsive therapy (ECT), which is the most effective short-term treatment for major depression (Sackeim et al., 2001), we determined changes in hippocampal cell proliferation immediately after treatment and neurogenesis 4 weeks later, a time frame corresponding to the full development of clinical response in humans ( $\sim 4$ weeks) (Segman et al., 1995). ECS was chosen over pharmacological antidepressants because it is a discrete, timelimited intervention allowing for examination of neuroplastic changes without confounds of residual drug levels. ECS also produces a more rapid and larger increase in neurogenesis in the rat hippocampus than any other antidepressant intervention (Malberg et al., 2000).

\section{Materials and Methods}

Subjects. All experimental procedures were conducted at the primate colony of the State University of New York Downstate with permission from its Animal Care and Use Committee and in accordance with the principles and procedures of the National Institutes of Health Guide for the Care and Use of Laboratory Animals. Young adult (3-6 years), individually housed, male bonnet monkeys (Macaca radiata) were divided into three groups, matched for age and weight: ECS $(n=6)$, sham (anesthesia only; $n=6)$, and untreated $(n=2)$.

ECS treatments. The ECS methods for treating monkeys were developed previously in our laboratory (Dwork et al., 2004) to model standard clinical administration of ECT (Sackeim et al., 1987). After sedation with ketamine $(10 \mathrm{mg} / \mathrm{kg}, \mathrm{i} . \mathrm{m}$.) and xylazine $(0.5 \mathrm{mg} / \mathrm{kg}$, i.m. $)$, general anesthesia was induced with methohexitol $(0.5 \mathrm{mg} / \mathrm{kg}$, i.v. $)$ and muscle relaxation induced with succinylcholine $(1.75 \mathrm{mg} / \mathrm{kg}$, i.v. $)$. For the ECS group, seizure threshold was quantified by the ascending method-of-limits procedure (Sackeim et al., 1987) and treatment administered at an electrical dose $350 \%$ above the seizure threshold using a constant current, bidirectional, brief-pulse ECS device, (Mecta, Tualatin, OR) with traditional bilateral frontotemporal electrode placement. Duration of seizure activity was assessed via two EEG channels. The sham group received only anesthesia and muscle relaxation. Both ECS and sham interventions were administered three times per week for 4 weeks. There were no signs of acute or chronic distress or significant weight loss in any of the animals.

BrdU injections and perfusions. Starting $3 \mathrm{~d}$ after completion of the intervention, each animal received four daily intravenous injections of bromodeoxyuridine (BrdU) at a dose of $100 \mathrm{mg} / \mathrm{kg}$. BrdU is a thymidine analog that is taken up by proliferating cells during the $S$ phase of the cell cycle (Nowakowski et al., 1989). Two hours after the last BrdU injection, four ECS, four sham, and two untreated animals (immediate-sacrifice group) were deeply anesthetized with thiopental $(12.5 \mathrm{mg} / \mathrm{kg}$, i.v. $)$ and perfused transcardially (Gould et al., 1999; Kornack and Rakic, 1999). The remaining two ECS and two sham animals were perfused 4 weeks later (delayed-sacrifice group). All brains were postfixed in $4 \%$ paraformaldehyde at $4^{\circ} \mathrm{C}$ and cryoprotected in sucrose. The left hippocampus was sectioned into $40 \mu \mathrm{m}$ free-floating slices.

Immunohistochemistry. In all subjects, every 40th section (approximately eight sections per antibody) through the rostrocaudal extent of the left hippocampus was immunostained with standard peroxidase methods (Nowakowski et al., 1989) to detect cells labeled with BrdU, Ki67 (antigen identified by monoclonal antibody Ki-67; an endogenously expressed marker of cell proliferation) (Yu et al., 1992), or B cell chronic lymphocytic lymphoma 2 (BCL2) using the following monoclonal primary antibodies: (1) anti-BrdU (1:200; Becton Dickinson, San Jose, CA); (2) anti-Ki67 (1:200; Vector Laboratories, Burlingame, CA);
(3) anti-BCL2 (1:200; Dako, High Wycombe, UK). The secondary antibody was biotinylated anti-mouse IgG (1:200; Vector Laboratories) visualized with avidin-biotin complex solution (Vector Laboratories) and diaminobenzidine (DAB; Sigma, St Louis, MO). Double labeling for BrdU and BCL2 was performed by nickel-enhanced DAB labeling for BrdU, followed by unenhanced DAB labeling for BCL2 in sections from both immediate and delayed-sacrifice animals.

In the delayed-sacrifice group, standard fluorescent methods (Gould et al., 1999; Kornack and Rakic, 1999) were used to double-label BrdUpositive cells with markers of cell differentiation: neuronal nuclei (NeuN; mature neurons); calretinin [immature granule cell neurons and subset of GABAergic interneurons (double bouquet cells)]; parvalbumin [subsets of GABAergic interneurons (including chandelier and some basket cells)]; GFAP (astrocytes); 2', 3' -cyclic nucleotide 3' phosphodiesterase (CNP; oligodendrocytes); antiplatelet/endothelial cell adhesion molecule (CD31; endothelial cells). BrdU-calretinin double labeling was performed in both the delayed- and immediate-sacrifice groups, because calretinin has been described in immature granule cells of the rat dentate gyrus (Brandt et al., 2003). The primary antibodies were rat anti-BrdU (1:400; Accurate, Westbury, NY) and one of the following: (1) mouse monoclonal anti-NeuN (1:200, Millipore, Temecula, CA), (2) rabbit anti-calretinin (1:200; Swant, Bellenzona, Switzerland), (3) mouse monoclonal anti-parvalbumin (1:2000; Swant), (4) mouse monoclonal anti-GFAP (1:200; Dako), (5) mouse monoclonal anti-CNP (1:100; Millipore), or (6) mouse monoclonal anti-CD31 (1:100; Accurate). The secondary antibodies were Alexa 488-conjugated goat anti-rat IgG and Alexa 568-conjugated goat anti-mouse IgG (or anti-rabbit IgG for calretinin; 1:200; Invitrogen, Carlsbad, CA). The positive control for BrdU labeling was monkey lip tissue, which has continuously dividing epithelial cells, and the negative control was hippocampal tissue from a test animal not injected with BrdU. For all other antibodies, exclusion of the primary antibody was the negative control. Gallyas suppressed silver stain (El-Khodor and Burke, 2002) was used to detect cell apoptosis and necrosis in the hippocampus (one section per animal) in both immediate- and delayed-sacrifice groups. Western blots of a bonnet macaque brain homogenate were conducted to confirm that all of the primary antibodies bound to bands of appropriate mobility.

Quantitative analysis. Two independent raters, masked to the identity of the animal and treatment condition, conducted all measurements of total BrdU, Ki67, and BCL2 counts. The rhesus macaque brain atlas by G. Paxinos et al. (2000) served as a guide because there are no brain atlases for bonnet macaques. The total number of unambiguously BrdU- or Ki67-labeled cells in the subgranular zone (SGZ) of the dentate gyrus of the hippocampus (defined as a two-cell-body-wide zone on either side of the border of the granule cell layer of the dentate gyrus and the hilus) (Gould et al., 1999; Kornack and Rakic, 1999) was counted on each slide using a $100 \times$ oil-immersion objective. The density of BrdU- or Ki67labeled cells per millimeter cubed of SGZ was estimated for each animal by dividing the total number of cells counted in the SGZ on all DABlabeled sections by the total volume of the SGZ in those sections. Silver staining for apoptotic cell bodies was examined in the dentate gyrus and hilus of the hippocampus. The expression of BCL2 gene product in the SGZ was viewed with a $40 \times$ objective and graded using the following semiquantitative four-point rating scale of staining intensity: 0 for no labeling; 1 , few cells were labeled; 2 , heavy labeling forming a noncontinuous band along the SGZ; and 3, intense labeling forming a continuous band along the entire length of the SGZ. The mean score for each animal was calculated and averaged across raters.

Fluorescent double labeling was evaluated using $60 \times$ oil-immersion objectives on a Zeiss (Oberkochen, Germany) LSM 510 META scanning confocal system attached to an Axiovert 200 inverted microscope or a Bio-Rad (Hercules, CA) Radiance 2100 confocal laser scanning system coupled to a Nikon (Tokyo, Japan) Eclipse E800 upright microscope. Double labeling was confirmed by acquiring z-stacks at $1 \mu \mathrm{m}$ intervals through cells of interest and by creating orthogonal views. Confocal analysis was conducted on a minimum of 25 BrdU-immunoreactive cells from each delayed sacrifice animal in at least three separate hippocampal sections to determine the percentage double-labeled with each of the maturational markers. These percentages were then multiplied by the 

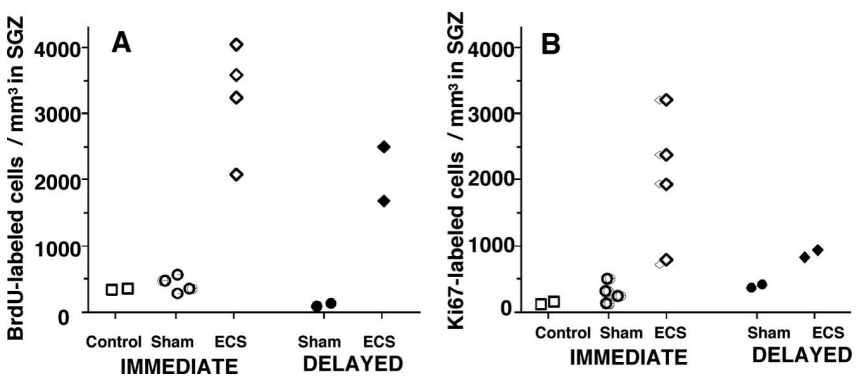

Figure 1. Density of proliferating cells in the SGZ of the dentate gyrus of the hippocampus. $A$, Two raters, masked to the intervention, counted BrdU-labeled cells in monkeys randomized to intervention group (control, sham, ECS) and time the animal was killed (immediate- vs delayed-sacrifice). The intraclass correlation coefficient across all counts was 0.97 . The density of BrdU-labeled cells in the SGZ was greater in the ECS group than the sham and control groups in the animals killed immediately after the treatment course $(t=6.3 ; \mathrm{df}=6 ; p=0.001)$ and in animals killed 4 weeks after the completion of the interventions $(t=4.8 ; \mathrm{df}=2 ; p=0.04)$. $B$, The density of Ki67-labeled cells in the SGZ was greater in the ECS group than the sham and control groups in the animals killed immediately after the treatment course $(t=3.4$; $\mathrm{df}=6$; $p=0.01)$ and in animals killed 4 weeks after the completion of the interventions $(t=10.7$; $\mathrm{df}=2 ; p=0.009$ ).

total density of BrdU-labeled cells in the SGZ, determined as described above, to estimate total densities of new cells of different lineages. This calculation is based on the assumption that the distribution of cell lineages is the same for the cells labeled for BrdU by fluorescence and enzymatic methods, although the latter is known to be more sensitive. Mean values for each animal were used to assess treatment effects by unpaired two-tailed $t$ tests.

\section{Results}

Repeated ECS markedly stimulated cellular proliferation in the dentate gyrus of the monkey hippocampus. The number of BrdU-labeled proliferating cells was increased by a factor of $\sim 10$ in the ECS group compared with sham ECS (sham) or no intervention (control) animals, both immediately after the interventions (immediate group) and 4 weeks later (delayed group) (Fig. $1 A)$. Conceivably, the increased BrdU labeling associated with ECS could have resulted from enhanced cerebral availability of BrdU stemming from ECS-mediated increases in cerebral blood flow or disruption of the blood-brain barrier (BBB) (Bolwig et al., 1977). To avoid this, we included a $72 \mathrm{~h}$ interval between the last seizure provocation and first BrdU injection, well beyond the duration of any systemic changes associated with ECS (Bolwig et al., 1977). Alternately, the increased labeling may have resulted from ECS-induced cell repair because BrdU is also taken up during DNA repair in nonmitotic cells (Nowakowski et al., 1989). To rule out this confound, we stained for Ki67 (Yu et al., 1992), a nuclear marker that is expressed only during the cell cycle and, thus, not seen in noncycling cells undergoing repair of DNA. Additionally, Ki67 is an endogenous molecule and, hence, not influenced by changes in blood flow or BBB permeability. ECS treatment increased the number of Ki67 stained cells relative to sham and controls (Fig. $1 B$ ) at both sacrifice points. Ki67 closely paralleled the values for BrdU in the immediate-sacrifice group where both markers label the same population of cells dividing at the time the animals were killed (Fig. 2). The results are similar to the parallel upregulation of BrdU and Ki67 labeling reported in the rat dentate gyrus during voluntary exercise (Eadie et al., 2005) and demonstrate that the increased BrdU counts in the ECS animals authentically reflect cell proliferation rates rather than enhanced bioavailability or DNA repair. In the immediate group, BrdU and Ki67 labeled cells that were essentially dividing at the same time. In the delayed group, however, BrdU labeled cells that

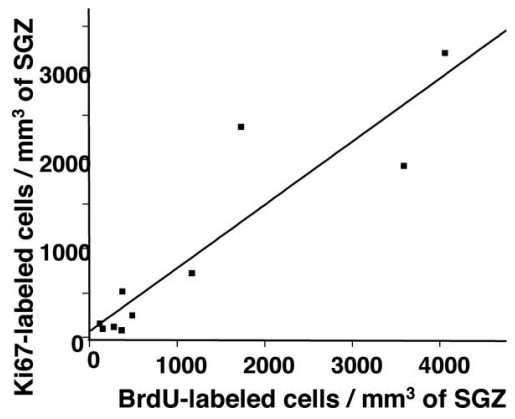

Figure 2. Correlation between BrdU-and Ki67-labeled cells. There was a positive correlation between densities of BrdU- and Ki67-labeled cells in the SGZ across all of the animals (ECS, sham, or control) killed immediately after the completion of interventions ( $r=0.92 ; \mathrm{df}=8$; $p=0.0002$ ).

were dividing at the time of the (BrdU) injections, whereas Ki67 was seen in cells dividing 4 weeks later, at the time the animals were killed. ECS increased the number of Ki67-labeled cells in the delayed group as well, indicating that the effect of treatment on proliferation persisted for at least 1 month. BrdU labeling in ECStreated animals was also elevated in the delayed group, suggesting that many of the cells proliferating in the immediate aftermath of ECS survived for at least 1 month.

The increased proliferation with ECS was not a response to cell damage. Hippocampal sections were stained with the Gallyas suppressed silver stain, which sensitively detects classical apoptosis, variant nonapoptotic cell death, and necrosis (El-Khodor and Burke, 2002). This method failed to detect any evidence of cell death in ECS- or sham-treated animals in both the immediateand delayed-sacrifice groups.

ECS stimulated the expression of the product of the neuroprotective gene BCL2 (Fig. $3 A, B$ ) in the SGZ of the dentate gyrus. None of the BrdU-labeled cells coexpressed BCL2 (Fig. 3C). BCL2 was increased both immediately after the treatment course and 4 weeks later (Fig. 4). This result is consistent with findings in (untreated) rhesus macaque monkeys, where neurogenesis in the temporal stream was accompanied by BCL2 immunoreactivity (Bernier et al., 2002). Although the colabeling of cells for BrdU and BCL2 might be expected, to our knowledge this has never been demonstrated, and we did not find it.

Four weeks after the completion of treatment (delayed group), the majority of the surviving (BrdU-labeled) new cells differentiated into mature neurons and endothelial cells (Fig. 5) in the SGZ of the ECS-treated and sham-treated animals. A markedly smaller proportion of BrdU-labeled cells were also labeled as glia (astrocytes or oligodendrocytes) (Fig. 6A). The percentage of BrdU-labeled cells double-labeled for each cytochemical marker did not differ between ECS and sham groups (Fig. $6 \mathrm{~B})$. Thus, ECS produced a marked increase in overall precursor cell proliferation, resulting in a substantial increase in the rate of neurogenesis.

Double labeling with BrdU and the calcium-binding protein calretinin was detected in ECS treated animals in the immediate group (Fig. 7), but not in the delayed group. Calretinin is expressed in a subpopulation of GABAergic interneurons (Liu et al., 2003 ) but has also been detected in immature granule cells of the rat dentate gyrus during the early postmitotic period, but not 2-3 weeks later, when it is exchanged for calbindin as the granule neurons attain maturity (Brandt et al., 2003). The transient expression of calretinin in newborn cells of the ECS-treated animals suggests that they are immature granule cells and not mature 

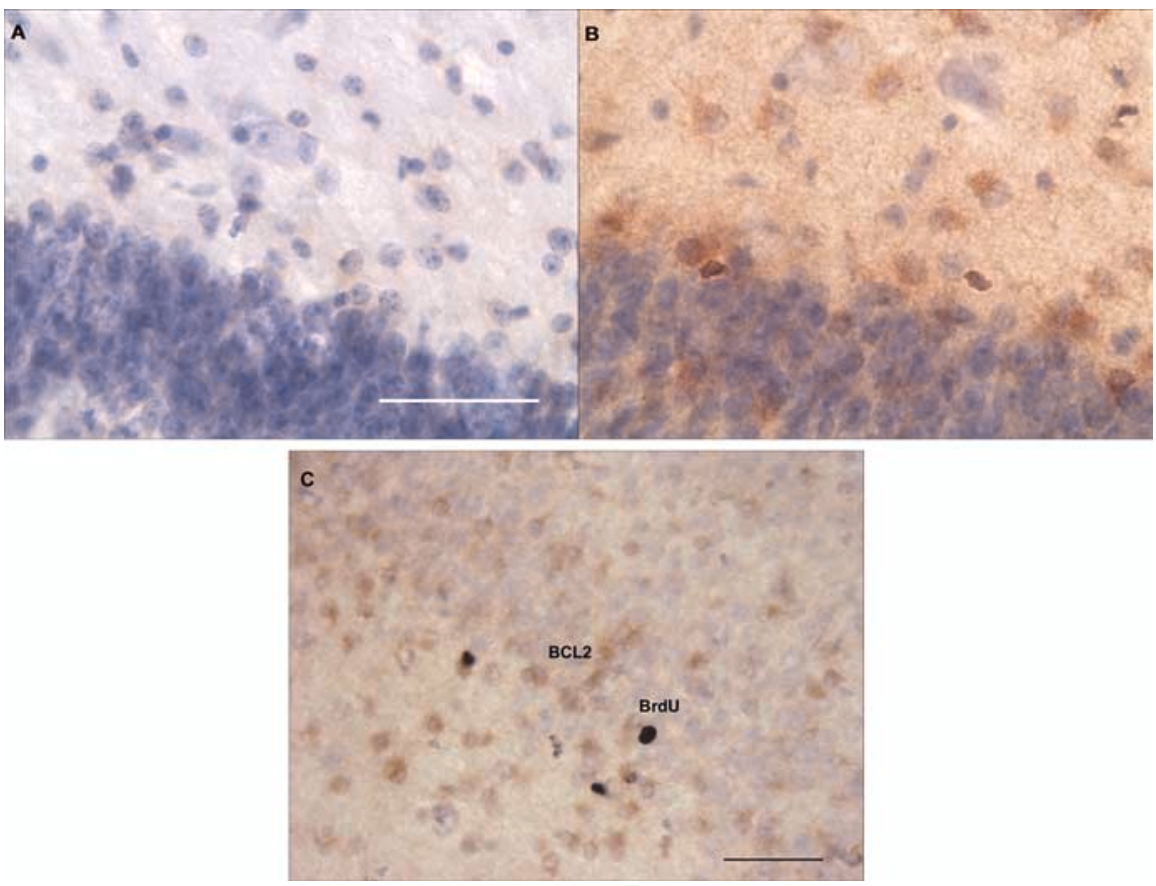

Figure 3. Images of $B C L 2$-labeled cells in the SGZ. Expression of the $B C L 2$ gene product (brown) in the dentate gyrus of animals killed immediately after the treatment course was significantly increased with ECS treatment. $\boldsymbol{A}$, Sham-treated animal. $\boldsymbol{B}$, ECStreated animal. $C$, In both treated and untreated animals killed immediately and 4 weeks after intervention and BrdU injections, no colabeling of BrdU and BCL2 was identified in nickel-enhanced peroxidase double labeling. The picture shows cells in the SGZ of an ECS-treated monkey labeled for BCL2 in the cytoplasm (brown) and BrdU in the nucleus with nickel enhancement (black). Scale bars: $A, 100 \mu \mathrm{m} ; C, 50 \mu \mathrm{m}$.

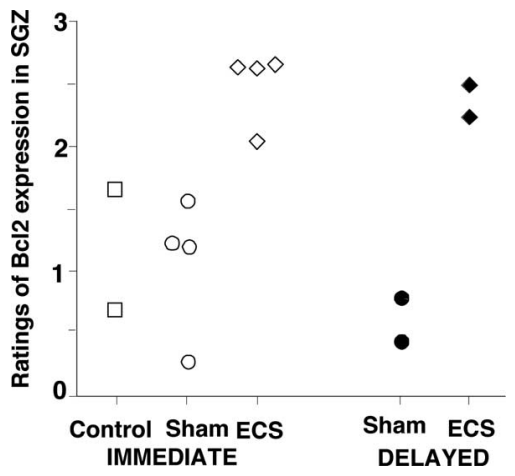

Figure 4. Ratings of BCL2 expression in the SGZ. The expression of the BCL2 gene product in the SGZ was graded using a four-point semiquantitative scale by two independent raters masked to treatment conditions (intraclass correlation coefficient, 0.97 ). The BCL2 ratings were greater in the SGZ of ECS-treated monkeys compared with sham or controls in animals killed immediately after the treatment course $(t=4.5 ; \mathrm{df}=6 ; p=0.004)$ and those killed 4 weeks after treatment $(t=8.0 ; \mathrm{df}=2 ; p=0.02)$.

interneurons. Approximately 10\% (9.54 \pm 0.31$)$ of BrdU-labeled cells in the SGZ of ECS-treated animals expressed calretinin whereas none was detected in sham subjects, suggesting a treatment effect $(t=30.3 ; \mathrm{df}=1 ; p=0.02)$. Similar percentages of calretinin-positive cells were seen in rats subjected to kainate seizures (Dominguez et al., 2003). None of the BrdU-labeled cells coexpressed parvalbumin.

\section{Discussion}

These results are the first to demonstrate that antidepressant therapy increases cell proliferation and neurogenesis in the nonhuman primate hippocampus. Previous studies in monkeys examined cell proliferation or neurogenesis under baseline condi- tions (Gould et al., 1999; Kornack and Rakic, 1999; Pencea et al., 2001; Bernier et al., 2002), ischemic injury (Tonchev et al., 2003), or in the setting of social stress (Gould et al., 1998; Coe et al., 2003). The increase in cell proliferation was substantially greater in ECS-treated monkeys than in rodents given equivalent numbers of ECS treatments (Madsen et al., 2000; Malberg et al., 2000; Scott et al., 2000; Hellsten et al., 2002). It is possible that with ECS, the electrical dosage above seizure threshold modulates the rate of neurogenesis. Many of the neurobiological effects of ECT, including efficacy and cognitive side effects (Sackeim et al., 1993), are sensitive to increases in electrical dosage. In this study, the dosage of bilateral ECS was set at a high level relative to seizure threshold (3.5 times seizure threshold), near the maximum commonly used in clinical treatment. In contrast, studies in rodents did not assess the extent to which electrical dosage exceeded threshold, and consequently may have used lesser relative doses leading to lower rates of proliferation.

The percentages of precursor cells that matured into neurons, glia, and endothelial cells were similar in both the treated and untreated monkeys, suggesting that ECS increases cell proliferation without altering maturational fates. This finding is consistent with rodent studies, in which antidepressant drugs and ECS appear to induce precursor cell proliferation (Malberg et al., 2000), whereas cell survival and maturational fate seem to be mediated by other factors such as brain-derived neurotrophic factor (Sairanen et al., 2005 ) and BCL2 (Kuhn et al., 2005). Approximately $60 \%$ of proliferating cells matured into neurons in the bonnet macaques, a proportion that is similar to neuronal differentiation rates at a comparable postmitotic stage in adult rhesus (Gould et al., 2001) and cynomolgus monkeys (Koketsu et al., 2006).

ECS also stimulated endothelial cell proliferation. Previous studies have shown that neurogenesis in the rodent hippocampus occurs in a vascular niche (Palmer et al., 2000). In rats, ECS stimulates endothelial cell proliferation in the rat frontal cortex (Madsen et al., 2005) and hippocampus (Hellsten et al., 2005), and these cells form new capillaries (angiogenesis). It is likely that ECS induced angiogenesis in these monkeys as well, but stereological studies of length density would be needed to confirm the growth of blood vessels.

This is the first demonstration that an antidepressant intervention stimulates BCL2 expression. BCL2 promotes differentiation of neuronal precursors (Oh et al., 1996) and offers neuronal protection during insults (Cao et al., 2002). In the mouse hippocampus, genetic overexpression of BCL2 robustly stimulates neurogenesis (Kuhn et al., 2005), and treatment with mood stabilizers increases BCL2 in conjunction with neurogenesis (Chen et al., 2000; Hao et al., 2004). Our results show a similar pattern of colocalization and coinduction of BCL2 and neurogenesis in ECS-treated monkeys. None of the proliferating cells in this study appeared to produce BCL2, indicating that pre-existing mature cells in the SGZ express the BCL2 gene product, which presumably induces the survival of nearby neuronal progenitors. 
Although there is no evidence that ECS induces tissue damage (Devanand et al., 1994), it is impossible to prove that this does not occur. Thus, one may question whether increased BrdU labeling represents a reparative process in response to occult cell injury or death. This seems unlikely for two reasons. First, we found no necrotic profiles on Gallyas suppressed silver stains of this cohort, and no neuronal pathology or reactive glial proliferation in an exhaustive study of hematoxylin and eosin-, cresyl violet-, and GFAP-stained sections of a similarly treated cohort of rhesus macaques (Dwork et al., 2004). After doubling the sample size, this rhesus cohort showed continued absence of pathology and no effects of treatment on neuronal or glial numbers in frontal cortex or hippocampus (A. J. Dwork, S. H. Lisanby, and B. Pakkenberg, unpublished observation)]. Thus, to attribute BrdU labeling of neurons to the repair of damaged DNA would require invocation of an unknown process that damages neuronal nuclei while only rarely killing the cell or producing recognizable morphological changes of the nucleus or cytoplasm on routine staining. Second, the increase in BrdU incorporation was closely paralleled by an increase in Ki67 expression that occurs only during cell proliferation, indicating that in the bulk of the cells with observable levels of BrdU, the thymidine analog had been incorporated during replication, rather than repair, of DNA. Nonetheless, we cannot entirely rule out the possibility of a neurogenic response to increased apoptosis, as described in antidepressant-treated mice (Sairanen et al., 2005). Apoptosis may not produce gliosis, and the apoptotic profiles may be too short-lived to allow detection.

Whereas ECS induces neurogenesis in the absence of tissue injury, chemically triggered seizures concurrently stimulate both neurogenesis and cell death (Nakagawa et al., 2000; Tooyama et al., 2002). Indeed, net neurogenesis can even be substantially reduced when chemical induction is prolonged and the rate of cell death overwhelms the pace of neuron generation (Hattiangady et al., 2004). Many of the cells lost during chemoconvulsant seizures are GABAergic interneurons (Sloviter, 1987) whereas most of the newly formed cells are excitatory granule cells (Parent et al., 1998), a combination of events that lowers seizure threshold and creates an epileptogenic state. In contrast, ECS increases postictal seizure threshold by enhancing GABAergic tone (Nutt et al., 1981; Bowdler et al., 1983). Both the increased seizure threshold (Perera et al., 2004) and enhanced GABA activity (Sanacora et al., 2003) seen postictally with ECT correlate with positive clinical outcome in depressed patients, which is consistent with our theories that the therapeutic benefits of ECT stem from GABAergic stabilization of mood (Sackeim et al., 1983). At a cellular level, ECS may enhance GABA transmission in the hippocampus by preserving GABAergic interneurons (Dalby et al., 1996) or by changing the function of granule cells to an inhibitory GABAergic phenotype (Sloviter et al., 1996). A third possibility is that ECS increases the GABAergic neuronal population in the hippocampus; $14 \%$ of newly generated neurons in the (untreated) rodent SGZ are GABAergic, parvalbumin-expressing basket-cell neurons (Liu et al., 2003). In our study, none of the BrdU-labeled hippocampal cells was immunoreactive for parval-
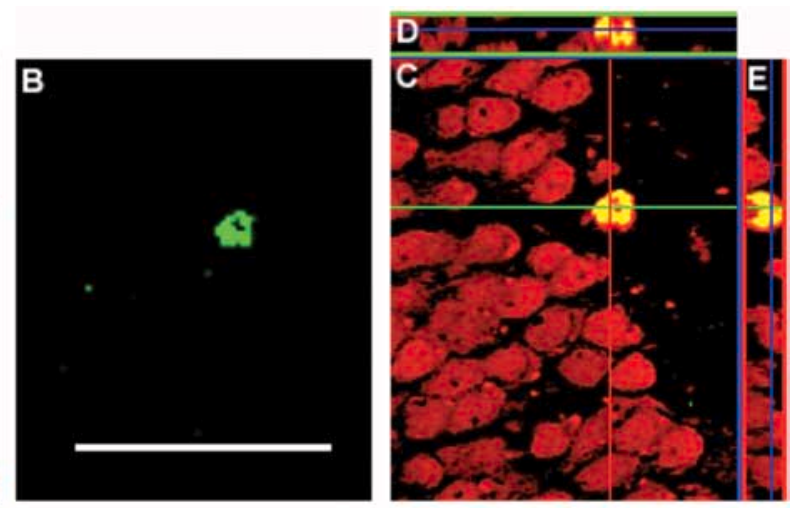

Figure 5. Images of cells double labeled with BrdU/NeuN and BrdU/CD31. A-E, Confocal images of a newly formed neuron in image of newly formed endothelial cells. Endothelial cytoplasm is labeled for CD31 (green) and two endothelial nuclei (indicated by arrows) in this capillary are labeled for BrdU (red). Scale bar: (in C) $\boldsymbol{A}-\boldsymbol{F}, 10 \mu \mathrm{m}$.

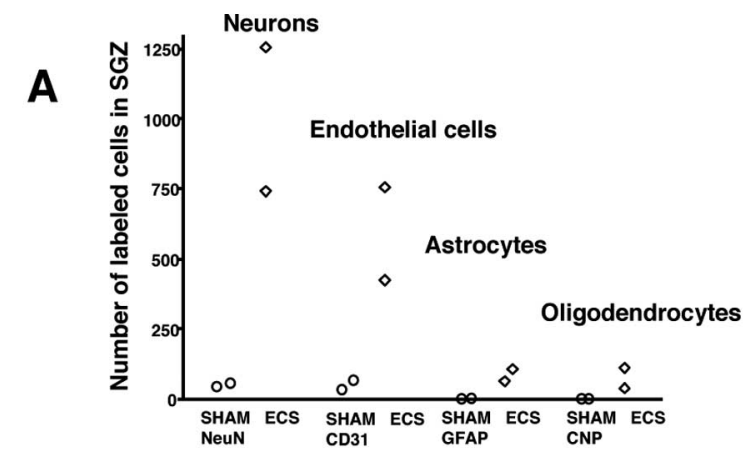

B
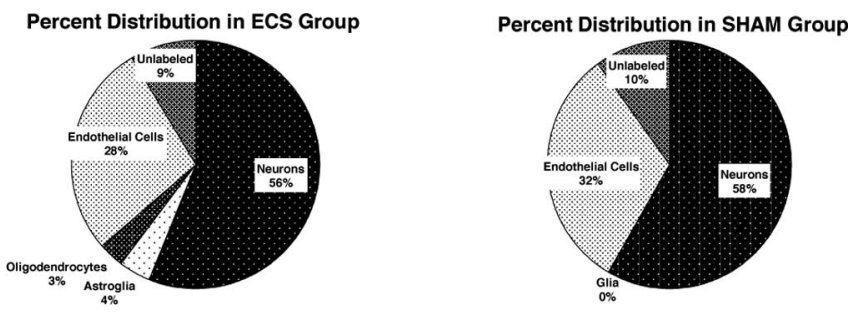

Figure 6. Maturational fate of proliferating cells in the SGZ. A, B, The hippocampal sections of animals (2 ECS and 2 sham) killed 4 weeks after injection of BrdU were double-labeled for BrdU and maturational markers for mature neurons (NeuN), astroglia (GFAP), oligodendrocytes (CNP), or endothelial cells (CD31). Confocal analysis was conducted on a minimum of 25 BrdUimmunoreactive cells in at least three separate hippocampal sections to determine the percentage double labeled with each of the maturational markers. These percentages were then multiplied by the total number of BrdU cells per millimeters cubed of the SGZ that was previously determined using peroxidase methods. $A$, Graph showing the number of each mature cell-type for each animal. $\boldsymbol{B}$, Pie charts showing the different percentages of mature cells in the ECS and sham groups.

bumin. However, our 4-week maturational window may have been too brief to detect parvalbumin expression in new neurons, which in rats appears 6 weeks after BrdU injection (Liu et al., 2003) and is not yet present 4 weeks after injection (Brandt et al., 2003).

In this experiment, ECS increased neurogenesis within a time frame that is generally consistent with maximal clinical benefits 


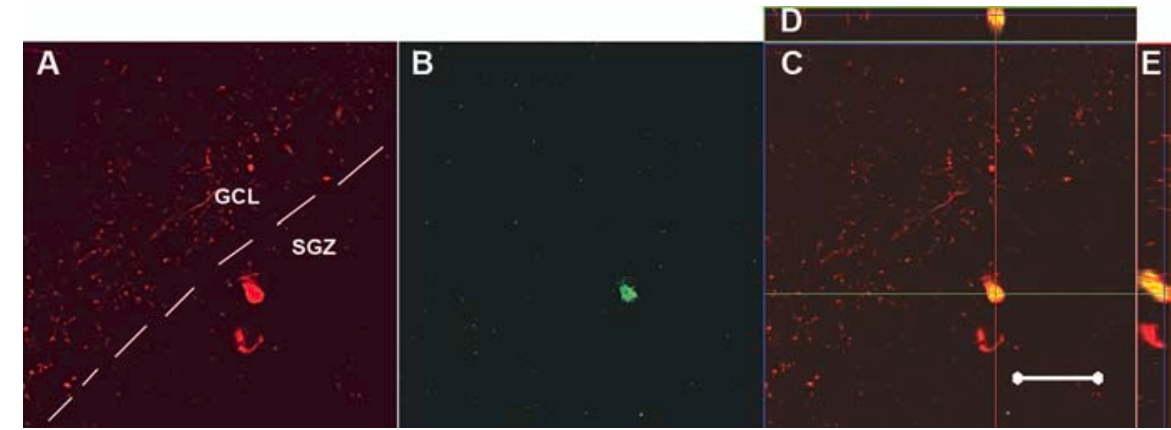

Figure 7. Confocal images of a cell double labeled with BrdU/calretinin in the SGZ.A-E, Confocal images of a newly generated calretinin-positive cell in the SGZ of an ECS-treated monkey killed immediately after the completion of treatment and BrdU injection. Calretinin is a $\mathrm{Ca}^{2+}$ binding protein typically seen in subpopulations of GABAergic interneurons, but this picture is of an immature granule cell, which transiently expresses calretinin during maturation. $\boldsymbol{A}$, Red labels calretinin. $\boldsymbol{B}, \mathrm{Green}$ labels BrdU. $\boldsymbol{C}$ Superimposed image of $\boldsymbol{A}$ and $\boldsymbol{B}$. D, Confocal stack resliced in the $x-z$ plane. $\boldsymbol{E}$, Confocal stack resliced in the $y-z$ plane. Scale bar, $20 \mu \mathrm{m} . \mathrm{GCL}$, Granule cell layer.

in humans. Depressed patients typically experience a $25-30 \%$ improvement in depressive symptoms after a week of ECT treatment and achieve full remission 2-4 weeks later (Segman et al., 1995; Nobler et al., 1997). In rats, new neurons attain functional synapses within 4 weeks of birth (van Praag et al., 2002; Jessberger and Kempermann, 2003). Seizures appear to accelerate this process. In the rat hippocampus, a single electrical seizure leads to an increase in cell proliferation within 3 d (Madsen et al., 2000; Hellsten et al., 2002), and pilocarpine-induced seizures accelerate the speed of functional integration to 2 weeks (OverstreetWadiche et al., 2006). Perhaps ECS increases the speed of neuronal maturation, and this accounts for its rapid clinical benefits.

The mechanisms by which ECS-generated new neurons might modulate mood (if indeed they do) are not known. Neurogenesis is involved in hippocampus-dependent trace fear conditioning (Shors et al., 2001) and transient place recognition (Madsen et al., 2003), two tasks that require the formation of temporary representations of space or events. Theoretically, suppressed neurogenesis could lead to inaccurate representations of external events in general, resulting in cognitive distortions associated with major depression (Greenberg and Beck, 1989). Stimulating neurogenesis could reverse these aberrant cognitive constructs. These theories are tempered by the fact that the functional role of new neurons remains to be determined. It is indeed possible that antidepressant-induced neurogenesis is an epiphenomenon unrelated to therapeutic effects. There are other potentially therapeutic mechanisms of antidepressants independent of neurogenesis, such as their effects on GABAergic activity discussed above, as well as direct and indirect effects on serotonergic transmission, the hypothalamic-pituitary adrenal axis, and expression of neurotrophic factors (Holsboer, 2000; Nutt, 2002; Duman, 2004).

In summary, we demonstrated that ECS significantly increases neurogenesis in the nonhuman primate brain. The similarities between the human and monkey brain and our faithful replication of clinical procedures suggest that similar changes occur in the brains of patients treated with ECT.

\section{References}

Altman J, Das GD (1965) Autoradiographic and histological evidence of postnatal hippocampal neurogenesis in rats. J Comp Neurol 124:319-335.

Bernier PJ, Bedard A, Vinet J, Levesque M, Parent A (2002) Newly generated neurons in the amygdala and adjoining cortex of adult primates. Proc Natl Acad Sci USA 99:11464-11469.

Bolwig TG, Hertz MM, Paulson OB, Spotoft H, Rafaelsen OJ (1977) The permeability of the blood-brain barrier during electrically induced seizures in man. Eur J Clin Invest 7:87-93.

Bowdler JM, Green AR, Minchin MC, Nutt DJ (1983) Regional GABA concentration and $[3 \mathrm{H}]$-diazepam binding in rat brain following repeated electroconvulsive shock. J Neural Transm 56:3-12.

Brandt MD, Jessberger S, Steiner B, Kronenberg G, Reuter K, Bick-Sander A, von der Behrens W, Kempermann G (2003) Transient calretinin expression defines early postmitotic step of neuronal differentiation in adult hippocampal neurogenesis of mice. Mol Cell Neurosci 24:603-613.

Cao YJ, Shibata T, Rainov NG (2002) Liposomemediated transfer of the bcl-2 gene results in neuroprotection after in vivo transient focal cerebral ischemia in an animal model. Gene Ther 9:415-419.

Chen G, Rajkowska G, Du F, Seraji-Bozorgzad N, Manji HK (2000) Enhancement of hippocampal neurogenesis by lithium. J Neuro-

chem 75:1729-1734.

Coe CL, Kramer M, Czeh B, Gould E, Reeves AJ, Kirschbaum C, Fuchs E (2003) Prenatal stress diminishes neurogenesis in the dentate gyrus of juvenile rhesus monkeys. Biol Psychiatry 54:1025-1034.

Czeh B, Michaelis T, Watanabe T, Frahm J, de Biurrun G, van Kampen M, Bartolomucci A, Fuchs E (2001) Stress-induced changes in cerebral metabolites, hippocampal volume, and cell proliferation are prevented by antidepressant treatment with tianeptine. Proc Natl Acad Sci USA 98:12796-12801.

Czeh B, Welt T, Fischer AK, Erhardt A, Schmitt W, Muller MB, Toschi N, Fuchs E, Keck ME (2002) Chronic psychosocial stress and concomitant repetitive transcranial magnetic stimulation: effects on stress hormone levels and adult hippocampal neurogenesis. Biol Psychiatry 52:1057-1065.

Dalby NO, Tonder N, Wolby DP, West M, Finsen B, Bolwig TG (1996) No loss of hippocampal hilar somatostatinergic neurons after repeated electroconvulsive shock: a combined stereological and in situ hybridization study. Biol Psychiatry 40:54-60.

Devanand DP, Dwork AJ, Hutchinson ER, Bolwig TG, Sackeim HA (1994) Does ECT alter brain structure? Am J Psychiatry 151:957-970.

Dominguez MI, Blasco-Ibanez JM, Crespo C, Marques-Mari AI, MartinezGuijarro FJ (2003) Calretinin/PSA-NCAM immunoreactive granule cells after hippocampal damage produced by kainic acid and DEDTC treatment in mouse. Brain Res 966:206-217.

Duman RS (2004) Role of neurotrophic factors in the etiology and treatment of mood disorders. Neuromolecular Med 5:11-25.

Dwork AJ, Arango V, Underwood M, Ilievski B, Rosoklija G, Sackeim HA, Lisanby SH (2004) Absence of histological lesions in primate models of ECT and magnetic seizure therapy. Am J Psychiatry 161:576-578.

Eadie BD, Redila VA, Christie BR (2005) Voluntary exercise alters the cytoarchitecture of the adult dentate gyrus by increasing cellular proliferation, dendritic complexity, and spine density. J Comp Neurol 486:39-47.

Eisch AJ, Barrot M, Schad CA, Self DW, Nestler EJ (2000) Opiates inhibit neurogenesis in the adult rat hippocampus. Proc Natl Acad Sci USA 97:7579-7584.

El-Khodor BF, Burke RE (2002) Medial forebrain bundle axotomy during development induces apoptosis in dopamine neurons of the substantia nigra and activation of caspases in their degenerating axons. J Comp Neurol 452:65-79.

Eriksson PS, Perfilieva E, Bjork-Eriksson T, Alborn AM, Nordborg C, Peterson DA, Gage FH (1998) Neurogenesis in the adult human hippocampus. Nat Med 4:1313-1317.

Fuchs E, Flugge G, Ohl F, Lucassen P, Vollmann-Honsdorf GK, Michaelis T (2001) Psychosocial stress, glucocorticoids, and structural alterations in the tree shrew hippocampus. Physiol Behav 73:285-291.

Gould E, McEwen BS, Tanapat P, Galea LA, Fuchs E (1997) Neurogenesis in the dentate gyrus of the adult tree shrew is regulated by psychosocial stress and NMDA receptor activation. J Neurosci 17:2492-2498.

Gould E, Tanapat P, McEwen BS, Flugge G, Fuchs E (1998) Proliferation of 
granule cell precursors in the dentate gyrus of adult monkeys is diminished by stress. Proc Natl Acad Sci USA 95:3168-3171.

Gould E, Reeves AJ, Fallah M, Tanapat P, Gross CG, Fuchs E (1999) Hippocampal neurogenesis in adult Old World primates. Proc Natl Acad Sci USA 96:5263-5267.

Gould E, Vail N, Wagers M, Gross CG (2001) Adult-generated hippocampal and neocortical neurons in macaques have a transient existence. Proc Natl Acad Sci USA 98:10910-10917.

Greenberg MS, Beck AT (1989) Depression versus anxiety: a test of the content-specificity hypothesis. J Abnorm Psychol 98:9-13.

Hao Y, Creson T, Zhang L, Li P, Du F, Yuan P, Gould TD, Manji HK, Chen G (2004) Mood stabilizer valproate promotes ERK pathway-dependent cortical neuronal growth and neurogenesis. J Neurosci 24:6590-6599.

Hattiangady B, Rao MS, Shetty AK (2004) Chronic temporal lobe epilepsy is associated with severely declined dentate neurogenesis in the adult hippocampus. Neurobiol Dis 17:473-490.

He J, Nixon K, Shetty AK, Crews FT (2005) Chronic alcohol exposure reduces hippocampal neurogenesis and dendritic growth of newborn neurons. Eur J Neurosci 21:2711-2720.

Hellsten J, Wennstrom M, Mohapel P, Ekdahl CT, Bengzon J, Tingstrom A (2002) Electroconvulsive seizures increase hippocampal neurogenesis after chronic corticosterone treatment. Eur J Neurosci 16:283-290.

Hellsten J, West MJ, Arvidsson A, Ekstrand J, Jansson L, Wennstrom M, Tingstrom A (2005) Electroconvulsive seizures induce angiogenesis in adult rat hippocampus. Biol Psychiatry 58:871-878.

Holsboer F (2000) The corticosteroid receptor hypothesis of depression. Neuropsychopharmacology 23:477-501.

Jessberger S, Kempermann G (2003) Adult-born hippocampal neurons mature into activity-dependent responsiveness. Eur J Neurosci 18:2707-2712.

Kempermann G, Kuhn HG, Gage FH (1997) More hippocampal neurons in adult mice living in an enriched environment. Nature 386:493-495.

Kodama M, Fujioka T, Duman RS (2004) Chronic olanzapine or fluoxetine administration increases cell proliferation in hippocampus and prefrontal cortex of adult rat. Biol Psychiatry 56:570-580.

Koketsu D, Furuichi Y, Maeda M, Matsuoka N, Miyamoto Y, Hisatsune T (2006) Increased number of new neurons in the olfactory bulb and hippocampus of adult non-human primates after focal ischemia. Exp Neurol 199:92-102.

Kornack DR, Rakic P (1999) Continuation of neurogenesis in the hippocampus of the adult macaque monkey. Proc Natl Acad Sci USA 96:5768-5773.

Kuhn HG, Biebl M, Wilhelm D, Li M, Friedlander RM, Winkler J (2005) Increased generation of granule cells in adult Bcl-2-overexpressing mice: a role for cell death during continued hippocampal neurogenesis. Eur J Neurosci 22:1907-1915.

Liu S, Wang J, Zhu D, Fu Y, Lukowiak K, Lu YM (2003) Generation of functional inhibitory neurons in the adult rat hippocampus. J Neurosci 23:732-736.

MacQueen GM, Campbell S, McEwen BS, Macdonald K, Amano S, Joffe RT, Nahmias C, Young LT (2003) Course of illness, hippocampal function, and hippocampal volume in major depression. Proc Natl Acad Sci USA 100:1387-1392.

Madsen TM, Treschow A, Bengzon J, Bolwig TG, Lindvall O, Tingstrom A (2000) Increased neurogenesis in a model of electroconvulsive therapy. Biol Psychiatry 47:1043-1049.

Madsen TM, Kristjansen PE, Bolwig TG, Wortwein G (2003) Arrested neuronal proliferation and impaired hippocampal function following fractionated brain irradiation in the adult rat. Neuroscience 119:635-642.

Madsen TM, Yeh DD, Valentine GW, Duman RS (2005) Electroconvulsive seizure treatment increases cell proliferation in rat frontal cortex. Neuropsychopharmacology 30:27-34.

Malberg JE, Duman RS (2003) Cell proliferation in adult hippocampus is decreased by inescapable stress: reversal by fluoxetine treatment. Neuropsychopharmacology 28:1562-1571.

Malberg JE, Eisch AJ, Nestler EJ, Duman RS (2000) Chronic antidepressant treatment increases neurogenesis in adult rat hippocampus. J Neurosci 20:9104-9110.

Manev H, Uz T, Smalheiser NR, Manev R (2001) Antidepressants alter cell proliferation in the adult brain in vivo and in neural cultures in vitro. Eur J Pharmacol 411:67-70.

Nakagawa E, Aimi Y, Yasuhara O, Tooyama I, Shimada M, McGeer PL,
Kimura H (2000) Enhancement of progenitor cell division in the dentate gyrus triggered by initial limbic seizures in rat models of epilepsy. Epilepsia 41:10-18.

Nobler MS, Sackeim HA, Moeller JR, Prudic J, Petkova E, Waternaux C (1997) Quantifying the speed of symptomatic improvement with electroconvulsive therapy: comparison of alternative statistical methods. Convuls Ther 13:208-221.

Nowakowski RS, Lewin SB, Miller MW (1989) Bromodeoxyuridine immunohistochemical determination of the lengths of the cell cycle and the DNA-synthetic phase for an anatomically defined population. J Neurocytol 18:311-318.

Nutt DJ (2002) The neuropharmacology of serotonin and noradrenaline in depression. Int Clin Psychopharmacol 17 [Suppl 1]:S1-S12.

Nutt DJ, Cowen PJ, Green AR (1981) Studies on the post-ictal rise in seizure threshold. Eur J Pharmacol 71:287-295.

O’Brien JT, Ames D, Schweitzer I, Colman P, Desmond P, Tress B (1996) Clinical and magnetic resonance imaging correlates of hypothalamicpituitary-adrenal axis function in depression and Alzheimer's disease. Br J Psychiatry 168:679-687.

Oh YJ, Swarzenski BC, O’Malley KL (1996) Overexpression of Bcl-2 in a murine dopaminergic neuronal cell line leads to neurite outgrowth. Neurosci Lett 202:161-164.

Overstreet-Wadiche LS, Bromberg DA, Bensen AL, Westbrook GL (2006) Seizures accelerate functional integration of adult-generated granule cells. J Neurosci 26:4095-4103.

Palmer TD, Willhoite AR, Gage FH (2000) Vascular niche for adult hippocampal neurogenesis. J Comp Neurol 425:479-494.

Parent JM, Janumpalli S, McNamara JO, Lowenstein DH (1998) Increased dentate granule cell neurogenesis following amygdala kindling in the adult rat. Neurosci Lett 247:9-12.

Paxinos G, Huang XF, Toga AW (2000) The rhesus monkey brain in stereotoxic coordinates. San Diego, CA: Academic.

Pencea V, Bingaman KD, Freedman LJ, Luskin MB (2001) Neurogenesis in the subventricular zone and rostral migratory stream of the neonatal and adult primate forebrain. Exp Neurol 172:1-16.

Perera TD, Lisanby SH (2000) Neurogenesis and depression. J Psychiatr Pract 6:322-333.

Perera TD, Luber B, Nobler MS, Prudic J, Anderson C, Sackeim HA (2004) Seizure expression during electroconvulsive therapy: relationships with clinical outcome and cognitive side effects. Neuropsychopharmacology 29:813-825.

Pham K, Nacher J, Hof PR, McEwen BS (2003) Repeated restraint stress suppresses neurogenesis and induces biphasic PSA-NCAM expression in the adult rat dentate gyrus. Eur J Neurosci 17:879-886.

Reif A, Fritzen S, Finger M, Strobel A, Lauer M, Schmitt A, Lesch KP (2006) Neural stem cell proliferation is decreased in schizophrenia, but not in depression. Mol Psychiatry 11:514-522.

Sackeim H, Decina P, Prohovnik I, Malitz S (1987) Seizure threshold in electroconvulsive therapy. Effects of sex, age, electrode placement, and number of treatments. Arch Gen Psychiatry 44:355-360.

Sackeim HA, Decina P, Prohovnik I, Malitz S, Resor SR (1983) Anticonvulsant and antidepressant properties of electroconvulsive therapy: a proposed mechanism of action. Biol Psychiatry 18:1301-1310.

Sackeim HA, Prudic J, Devanand DP, Kiersky JE, Fitzsimons L, Moody BJ, McElhiney MC, Coleman EA, Settembrino JM (1993) Effects of stimulus intensity and electrode placement on the efficacy and cognitive effects of electroconvulsive therapy. N Engl J Med 328:839-846.

Sackeim HA, Haskett RF, Mulsant BH, Thase ME, Mann JJ, Pettinati HM, Greenberg RM, Crowe RR, Cooper TB, Prudic J (2001) Continuation pharmacotherapy in the prevention of relapse following electroconvulsive therapy: a randomized controlled trial. JAMA 285:1299-1307.

Sairanen M, Lucas G, Ernfors P, Castren M, Castren E (2005) Brain-derived neurotrophic factor and antidepressant drugs have different but coordinated effects on neuronal turnover, proliferation, and survival in the adult dentate gyrus. J Neurosci 25:1089-1094.

Sanacora G, Mason GF, Rothman DL, Hyder F, Ciarcia JJ, Ostroff RB, Berman RM, Krystal JH (2003) Increased cortical GABA concentrations in depressed patients receiving ECT. Am J Psychiatry 160:577-579.

Santarelli L, Saxe M, Gross C, Surget A, Battaglia F, Dulawa S, Weisstaub N, Lee J, Duman R, Arancio O, Belzung C, Hen R (2003) Requirement of hippocampal neurogenesis for the behavioral effects of antidepressants. Science 301:805-809. 
Scott BW, Wojtowicz JM, Burnham WM (2000) Neurogenesis in the dentate gyrus of the rat following electroconvulsive shock seizures. Exp Neurol 165:231-236.

Segman RH, Shapira B, Gorfine M, Lerer B (1995) Onset and time course of antidepressant action: psychopharmacological implications of a controlled trial of electroconvulsive therapy. Psychopharmacology (Berl) 119:440-448.

Sheline YI, Sanghavi M, Mintun MA, Gado MH (1999) Depression duration but not age predicts hippocampal volume loss in medically healthy women with recurrent major depression. J Neurosci 19:5034-5043.

Shors TJ, Miesegaes G, Beylin A, Zhao M, Rydel T, Gould E (2001) Neurogenesis in the adult is involved in the formation of trace memories. Nature 410:372-376.

Sloviter RS (1987) Decreased hippocampal inhibition and a selective loss of interneurons in experimental epilepsy. Science 235:73-76.

Sloviter RS, Dichter MA, Rachinsky TL, Dean E, Goodman JH, Sollas AL, Martin DL (1996) Basal expression and induction of glutamate decarboxylase and GABA in excitatory granule cells of the rat and monkey hippocampal dentate gyrus. J Comp Neurol 373:593-618.

Tonchev AB, Yamashima T, Zhao L, Okano HJ, Okano H (2003) Prolifera- tion of neural and neuronal progenitors after global brain ischemia in young adult macaque monkeys. Mol Cell Neurosci 23:292-301.

Tooyama I, Bellier JP, Park M, Minnasch P, Uemura S, Hisano T, Iwami M, Aimi Y, Yasuhara O, Kimura H (2002) Morphologic study of neuronal death, glial activation, and progenitor cell division in the hippocampus of rat models of epilepsy. Epilepsia 43:39-43.

van Praag H, Kempermann G, Gage FH (1999) Running increases cell proliferation and neurogenesis in the adult mouse dentate gyrus. Nat Neurosci 2:266-270.

van Praag H, Schinder AF, Christie BR, Toni N, Palmer TD, Gage FH (2002) Functional neurogenesis in the adult hippocampus. Nature 415:1030-1034.

Vollmayr B, Simonis C, Weber S, Gass P, Henn F (2003) Reduced cell proliferation in the dentate gyrus is not correlated with the development of learned helplessness. Biol Psychiatry 54:1035-1040.

Wakade CG, Mahadik SP, Waller JL, Chiu FC (2002) Atypical neuroleptics stimulate neurogenesis in adult rat brain. J Neurosci Res 69:72-79.

Yu CC, Woods AL, Levison DA (1992) The assessment of cellular proliferation by immunohistochemistry: a review of currently available methods and their applications. Histochem J 24:121-131. 